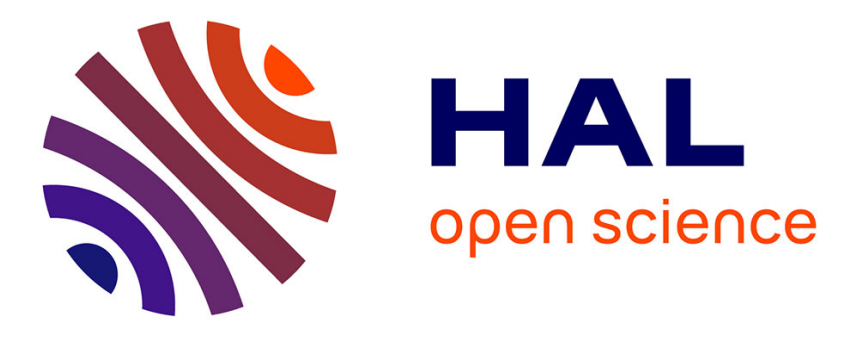

\title{
Versatile Device for the Study of Coupling Properties in Multifunctional Materials. Example: Ni-(Co)-Mn-In Heusler Materials
}

Hugo Dufour, Oneil Goisot, Anne Gerardin, Emilio Barria, Pierre Courtois, G Donnier- Valentin, Jerome Debray, Laureline Porcar, Daniel Bourgault

\section{To cite this version:}

Hugo Dufour, Oneil Goisot, Anne Gerardin, Emilio Barria, Pierre Courtois, et al.. Versatile Device for the Study of Coupling Properties in Multifunctional Materials. Example: Ni-(Co)-Mn-In Heusler Materials. IEEE Transactions on Instrumentation and Measurement, 2021, 70, pp.6008212. 10.1109/TIM.2021.3086896 . hal-03331740

\author{
HAL Id: hal-03331740 \\ https://hal.science/hal-03331740
}

Submitted on 2 Sep 2021

HAL is a multi-disciplinary open access archive for the deposit and dissemination of scientific research documents, whether they are published or not. The documents may come from teaching and research institutions in France or abroad, or from public or private research centers.
L'archive ouverte pluridisciplinaire HAL, est destinée au dépôt et à la diffusion de documents scientifiques de niveau recherche, publiés ou non, émanant des établissements d'enseignement et de recherche français ou étrangers, des laboratoires publics ou privés. 


\title{
Versatile device for the study of coupling properties in multifunctional materials. Example : Ni-(Co)-Mn-In Heusler materials
}

\author{
H. Dufour ${ }^{(1,2)}$, O. Goisot ${ }^{(1,2)}$, A. Gerardin ${ }^{(1,2)}$, E. Barria ${ }^{(1,2)}$, P. Courtois $^{(3)}$, G. Donnier- \\ Valentin $^{(1,2)}$, J. Debray ${ }^{(1,2)}$, L. Porcar ${ }^{(1,2)}$, D. Bourgault ${ }^{(1,2, a)}$, \\ (1) Univ. Grenoble Alpes, Institut Néel, F-38042 Grenoble, France. \\ (2) Centre National de la Recherche Scientifique / Institut Néel, 25 Avenue des Martyrs, \\ BP 166, 38042 Grenoble Cedex 9, France \\ (3) Institut Laue Langevin, 38000 Grenoble, France.
}

\begin{abstract}
We report on a versatile experimental set-up for the study of the electro-magneto-elastothermal coupling for bulk materials having coupling properties. The set-up enables measurement of stress and electrical resistivity in a $80 \mathrm{~K}-450 \mathrm{~K}$ temperature range under controlled uniaxial pressure in a magnetic field up to $8 \mathrm{~T}$.

The strong influence of uniaxial pressure and magnetic field on strain and transport properties is shown for Ni-Co-Mn-In Heusler single crystal material. Phase transformation, magnetostress and Magnetic Field Induced Phase Transformation and elastocaloric effect can be estimated using this versatile set-up.

This device is very complementary to the studies focused on the modeling of Thermo-ElectroMagneto-Mechanical behavior for functional materials.
\end{abstract}

\section{Corresponding author}

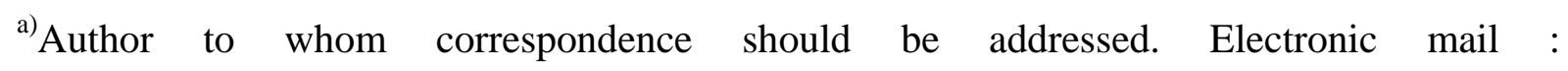
daniel.bourgault@ neel.cnrs.fr 


\section{Introduction}

With the strong interest in multi field properties of multifunctional materials, versatile devices for the study of coupling properties are necessary. For Ni-Mn-X (X=Ga, Sn, Sb, In...), GdGe-Si or Fe-Rh systems showing elasto-magneto-thermo-electric coupling, such experimental works are rarely reported in the literature ${ }^{1-3}$. It deserves to be developed for a better understanding of functional properties in addition to simulation and modelling studies ${ }^{4-8}$.

The influence of isostatic or uniaxial pressure on electronic properties has been demonstrated in many materials such as superconductors ${ }^{9-13}$, heavy fermions ${ }^{14-17}$, magnetic materials ${ }^{18,19}$, organic conductors ${ }^{20,21}$, semiconductors ${ }^{22,23}$. Most of the set-ups use the clamp technique with a pressure locked at room temperature. In this case, thermal expansion and/or volume discontinuity during phase transition of the measured materials lead to pressure variation during measurement at temperatures different from $300 \mathrm{~K}$. Only few experimental setups are based on uniaxial pressure tuning for electrical resistivity versus temperature measurements ${ }^{3,24-28}$.

We recently developed a uniaxial pressure set-up for piezoresistance and magnetoresistance measurements in Heusler materials ${ }^{29}$. In this device, strain measurement was not possible and the dimensions of the samples did not require thermal regulation optimization under loading. A magneto-thermo-mechanical characterization device implemented by Bruno et al. ${ }^{3}$ is capable of uniaxial pressure at load levels close to $5 \mathrm{kN}$ collinearly with applied fields up to $9 \mathrm{~T}$ between temperatures of $173 \mathrm{~K}$ and $393 \mathrm{~K}$. Uniaxial stress, strain, temperature, magnetic field, and volumetric average magnetization can be simultaneously measured with this device. Gràcia-Condal et al. developed an experimental setup for the analysis of caloric effects $(200 \mathrm{~K}-400 \mathrm{~K})$ driven by uniaxial compression $(1.2 \mathrm{kN})$ and magnetic field $(6 \mathrm{~T})^{30}$. 
Our device enables electrical resistivity and strain measurements simultaneously under uniaxial stress (up to $1 \mathrm{GPa}$ ) and high magnetic fields up to $8 \mathrm{~T}$ within a large temperature window between $80 \mathrm{~K}$ and $450 \mathrm{~K}$. The thermal regulation of the sample under loading has been optimized using two cooling/heating elements localized at the top and the bottom of the sample. The thermal gradient along the length of the sample is thereby considerably reduced. This is not the case for systems under loading having only one regulating element in contact with the sample.

We have chosen some compositions in Ni-Mn based Heusler system as an example of our device's application. This material is obviously not exhaustive, many other material families with functional properties can be tested with the set-up presented in this paper. Heusler Ni-Mn based materials have extensively been studied during these last years because of their functional properties induced during the first-order magnetic transition. Under cooling or heating, these alloys change from a martensite phase to an austenite phase for which physical properties such as electrical resistivity or magnetic state are different. Among these properties, magnetic superelasticity, giant magnetoresistance ${ }^{34-37}$, piezoresistance ${ }^{29,38}$, magnetocaloric ${ }^{34,39-42}$ and elastocaloric effects ${ }^{43-47}$ are of particular interest. Dedicated experimental devices must however be developed to further understand the coupling properties of such materials. In this context, the versatility of our set-up needs to be highlighted. The use of $\mathrm{Ni}_{45} \mathrm{Co}_{5} \mathrm{Mn}_{37.5} \operatorname{In}_{12.5}$ and $\mathrm{Ni}_{50} \mathrm{Mn}_{34.5} \mathrm{In}_{15.5}$ Heusler single crystal measurements is to our sense a convincing demonstration.

\section{Experimental set up description}

A picture and a schematic representation of the whole system are respectively visible in figures $1 \mathrm{a}$ and $1 \mathrm{~b}$. The whole system consists in a vacuum chamber (1) made of a $2 \mathrm{~mm}$ thick 
stainless steel tube and two flanges (2 and 3) on which top (red dashed line) and bottom (blue dashed line) parts of the system are maintained. The sample is located on the fixed bottom part, and the top part can move vertically for a uniaxial stress on the sample. This chamber can be introduced into the room temperature bore of a superconducting coil (4) capable of reaching magnetic fields up to $8 \mathrm{~T}$ with a maximum field rate of $0.7 \mathrm{~T} / \mathrm{min}$. Both parts are equipped with a servo-controlled temperature regulation as explained below. Materials used for the set-up fabrication were chosen to limit the induced magnetic force in an $8 \mathrm{~T}$ magnetic field and were adapted to the $77 \mathrm{~K}-450 \mathrm{~K}$ working temperature range.

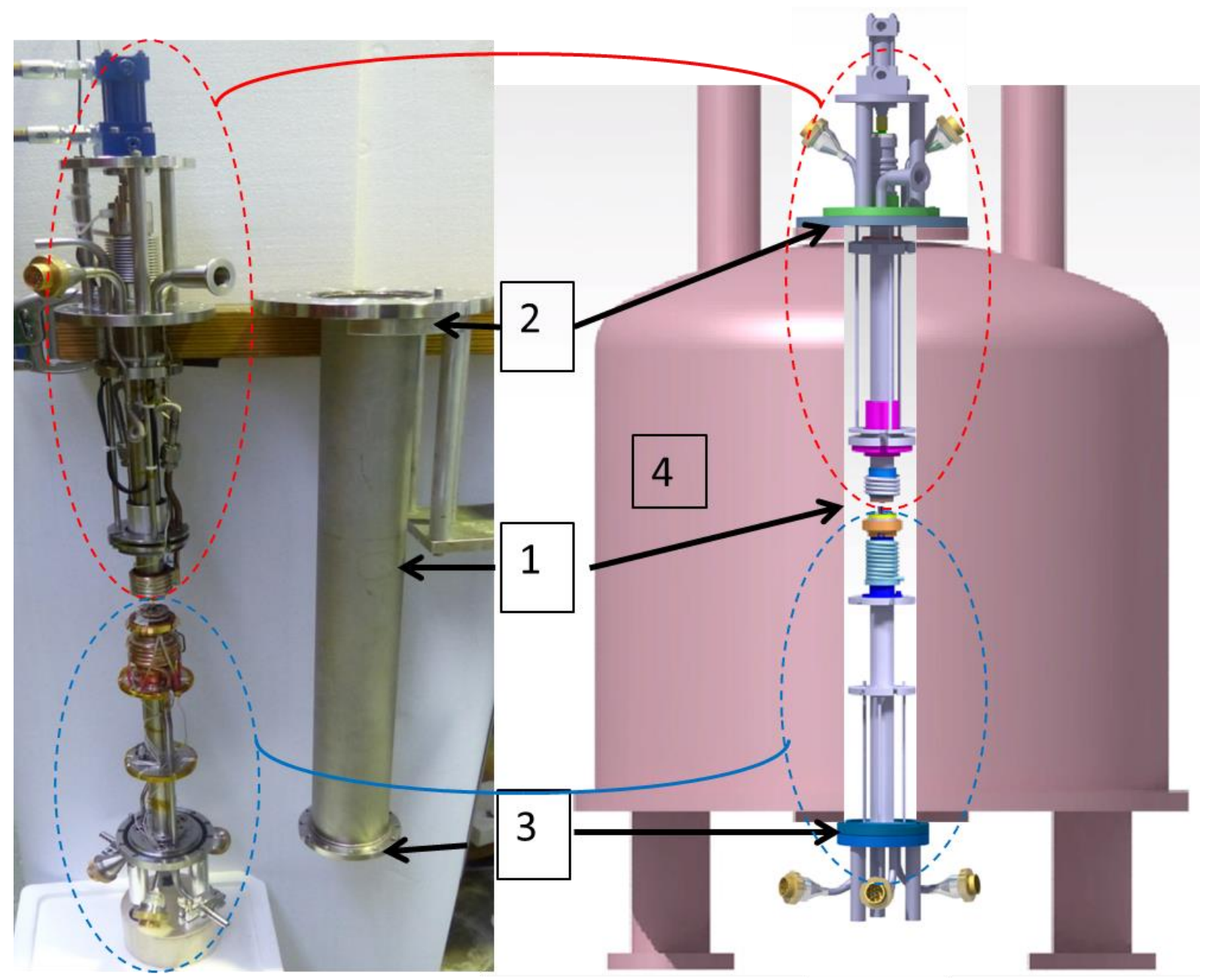

a)

b)

Figure 1: a) Picture of the top (red dashed line) and bottom (blue dashed line) parts of the set-up and vacuum chamber (1) with two flanges $(2,3)$. b) Schematic view of the top and 
bottom parts inserted in the $120 \mathrm{~mm}$ diameter room temperature bore of a superconducting magnetic coil (4).

Top part

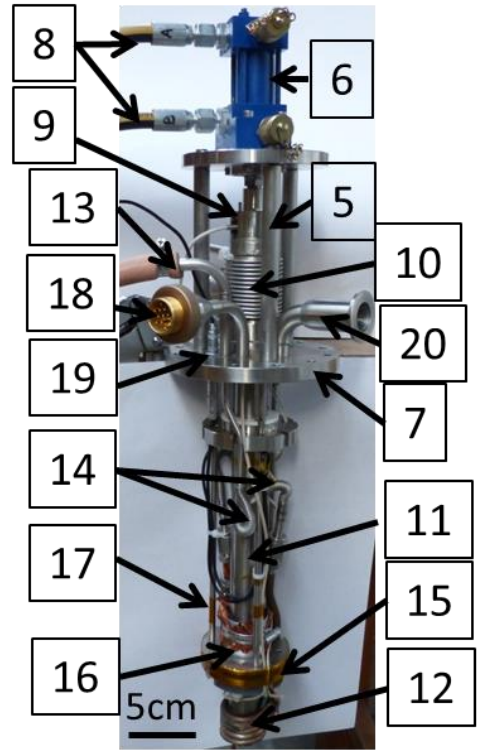

a)

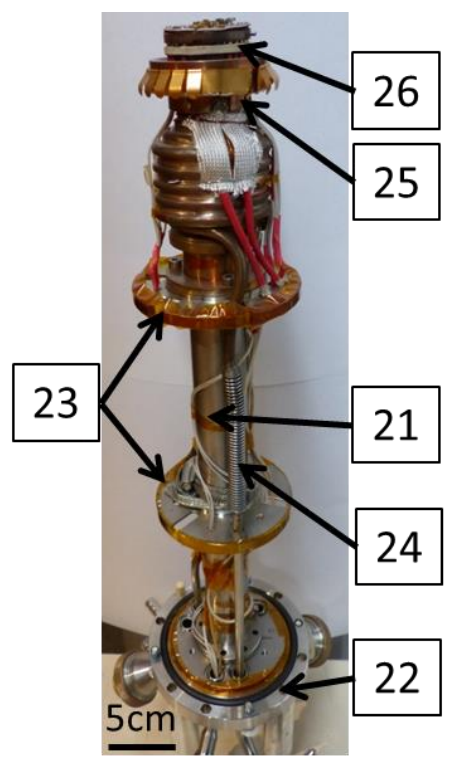

b)

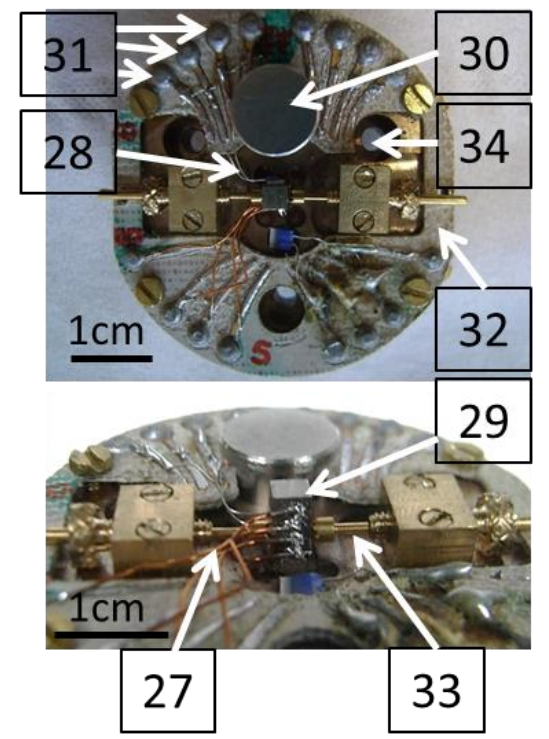

c)

Figure 2 : a) Top part of the set-up: (5) Holding tubes, (6) hydraulic actuator, (7) upper flange, (8) oil inlet and outlet, (9) load cell, (10) tombac allowing linear displacement of the compression tube, (11) compression tube, (12) liquid nitrogen exchanger, (13) liquid nitrogen inlet, (14) liquid nitrogen tombac, (15) centering ring, (16) polymer guiding ring, (17) holding rod of centering ring, (18) plug connector, (19) capacitive displacement sensor connector, (20) vacuum connector.

b) Bottom part of the set-up: (21) fixed compression tube, (22) bottom flange, (23) centering ring, (24) liquid nitrogen inlet, (25) CuBe block, (26) sample holder.

c) Top and side views of the sample holder: (27) four connected wires for electrical resistivity measurements, (28) Pt $100 \Omega$ thermal probe glued on sample, (29) sample, (30) 
capacitive sensor, (31) 16 electrical connections, (32) fiberglass sheet, (33) spring pins for sample support, (34) holes for clamping screws.

Figure 2a shows the top part of the versatile device able to move along the vertical axis parallel to the magnetic field and stress axis. Maintained by holding tubes (5), a hydraulic actuator (6) is placed on the upper flange (7) and is connected to a compression unit via the oil inlet and outlet tubes (8). A load cell (9) located under the actuator measures the force applied to the system. It is in contact with a piece welded to a tombac (10) which allows a linear displacement of the compression tube (11) located in the vacuum chamber. At the end of this compression tube, the liquid nitrogen exchanger (12), thermometer and heating system for the regulation (not visible on picture $2 \mathrm{a}$ ) are in contact with a $\mathrm{Cu}$-Be cylindrical plate. The exchanger is connected to the liquid nitrogen inlet (13) and outlet by means of a $6 \mathrm{~mm}$ diameter tombac (14). The flexibility of the liquid nitrogen circuit allows the system to be mobile whatever the temperature, thus enabling a constant stress in spite of thermal expansions and deformations of the measured material. The force exerted by the actuator on the compression tube is transmitted vertically thanks to two centering rings (15) and two polymer guide rings (16) to limit friction in the temperature range. The two centering rings are held to the upper flange by three $6 \mathrm{~mm}$ stainless steel rods (17). On the surface of the upper flange 3, airtight connectors are also visible: an electrical plug connector (18) which supplies power to the heating cartridge and allows thermometer measurements, a connector for the measurement of the capacitive displacement sensor (19) and the vacuum connector (20) connected to a secondary vacuum pump.

\section{Bottom part}


Figure $2 \mathrm{~b}$ shows the bottom part of the set-up. A fixed compression tube (21) of $30 \mathrm{~mm}$ diameter is welded to the bottom flange (22). The centering rings (23) in contact with the vacuum chamber prevent the tube from twisting when stress is applied. Rigid nitrogen tubes assembled with tombac tubes (24) enable the liquid nitrogen flowing in the exchanger welded to the $\mathrm{Cu}-\mathrm{Be}$ block (25) on which the sample holder (26) is located. Heating cartridge and thermometer (not visible) are also located in the $\mathrm{Cu}$-Be block for the regulation of the bottom part. The sample holder can be disconnected from this bottom part in order to facilitate the mounting of the sample under binocular.

\section{Sample holder}

Figure 2c shows top and side views of the sample holder. Four electrical contacts (27) are connected for the transport measurement and a thermometer (28) is glued to the sample surface (29). An accuracy alignment of the capacitive sensor (30) with the top of the measured sample is necessary and must be realized only under optical magnification. The sample holder has 16 electrical connections (31) for the measurement of several thermal sensors or for 4-point resistivity measurements. A thin sheet of fiberglass (32) is bonded to the surface of the $\mathrm{Cu}-\mathrm{Be}$ plate for insulation between electrical connections. This sheet is drilled in the center so that the sample is in perfect mechanical contact with the $\mathrm{Cu}-\mathrm{Be}$ plate. Two small spring pins (33) apply a low horizontal pressure on both sides of the parallelepipedic sample to ensure sample positioning during the reconnection of the sample holder and the introduction of the bottom part into the vacuum chamber. Thermal contact between sample holder and $\mathrm{Cu}-\mathrm{Be}$ block is then ensured by three clamping screws (34) and using Apiezon thermal grease. 


\section{Stress application-strain measurement}

After both top and bottom parts are introduced into the vertical vacuum chamber, the pressure is applied by the hydraulic actuator. The compression tube of the top part meets the upper side of the sample. The sample is then in contact with the two $\mathrm{Cu}$-Be plates with the two armatures of the capacitive sensor ranging from 0 to $0.5 \mathrm{~mm}$. By increasing pressure the strain of the sample is measured using the change of the armature distance.

A typical sample size of $5 \times 1 \times 1.5 \mathrm{~mm}^{3}$ is sandwiched between the two $\mathrm{Cu}-\mathrm{Be}$ plates with the long length along the magnetic field and stress axis. The maximum force applied to the sample is $3 \mathrm{kN}$ using the regulated hydraulic actuator. The system is largely able to support 1 $\mathrm{GPa}\left(150 \mathrm{Kg}\right.$ on a sample of $1.5 \mathrm{~mm}^{2}$ in section) on a short length. This has been checked with a low brittleness material as $\mathrm{Cu}-\mathrm{Be}$.

Force was measured with a Measurement Specialities XFC load cell capable of $5 \mathrm{kN}$ measurements. The load cell is placed outside the bore of the superconducting coil to reduce the magnetic field applied and is in serial with the piston and the sample. Stress $\sigma$ was calculated by dividing the force with the sample cross-section. Uniaxial pressure was applied by the hydraulic actuator with pressure regulation to balance volume variations due to phase transformation and thermal dilatation of the different materials used in the set-up. In this way, thermal scanning was realized under constant uniaxial pressure. For uniaxial forces lower than $200 \mathrm{~N}$, weights stacked on a flange replaced the hydraulic actuator.

The strain was measured using a Fogale MCC2 capacitive sensor and MC900 electronic module. The sensor, located close to the sample, can measure a strain between 0 and $0.5 \mathrm{~mm}$ along the stress axis in the compression mode. 


\section{Transport measurements}

The four-point-probe method for resistivity measurements is applied to bulk sample. DC currents of several milliamps are obtained by a Keithley 2602 generator, and voltage is measured using an Agilent 34970A multimeter. Acquisition and control of the measurements are performed using LabVIEW 7 software. The top and bottom parts of the device are electrically insulated to enable transport measurements during uniaxial pressure.

\section{Thermal regulation}

A special attention was dedicated to the thermal regulation of the set-up. Indeed, the transformation temperatures of Ni-Mn based Heusler systems strongly depend on composition and spread in a very wide range $e^{48,49}$. In addition, kinetic effects have a strong influence on phase transformation ${ }^{50-54}$. The set-up is consequently able to cool down to $80 \mathrm{~K}$ and heat up to $450 \mathrm{~K}$ with a constant rate close to $4 \mathrm{~K} / \mathrm{min}$ to cover the transformation temperature range of $\mathrm{Ni}_{50-\mathrm{x}} \mathrm{Co}_{\mathrm{x}} \mathrm{Mn}_{50-\mathrm{y}} \mathrm{In}_{\mathrm{y}}(0 \leq \mathrm{x} \leq 7.5$ and $10 \leq \mathrm{y} \leq 20)$ materials. This is shown in figure $\mathrm{S} 1$ in supplementary information. The rates of cool down and heat up are respectively -3.8 and $3.7 \mathrm{~K} / \mathrm{min}$ between $90 \mathrm{~K}$ and $420 \mathrm{~K}$.

The synoptic scheme describing the thermal regulation of both parts of the set-up is shown in figure 3. Electrical resistivity and strain acquisition are also represented in the scheme. 


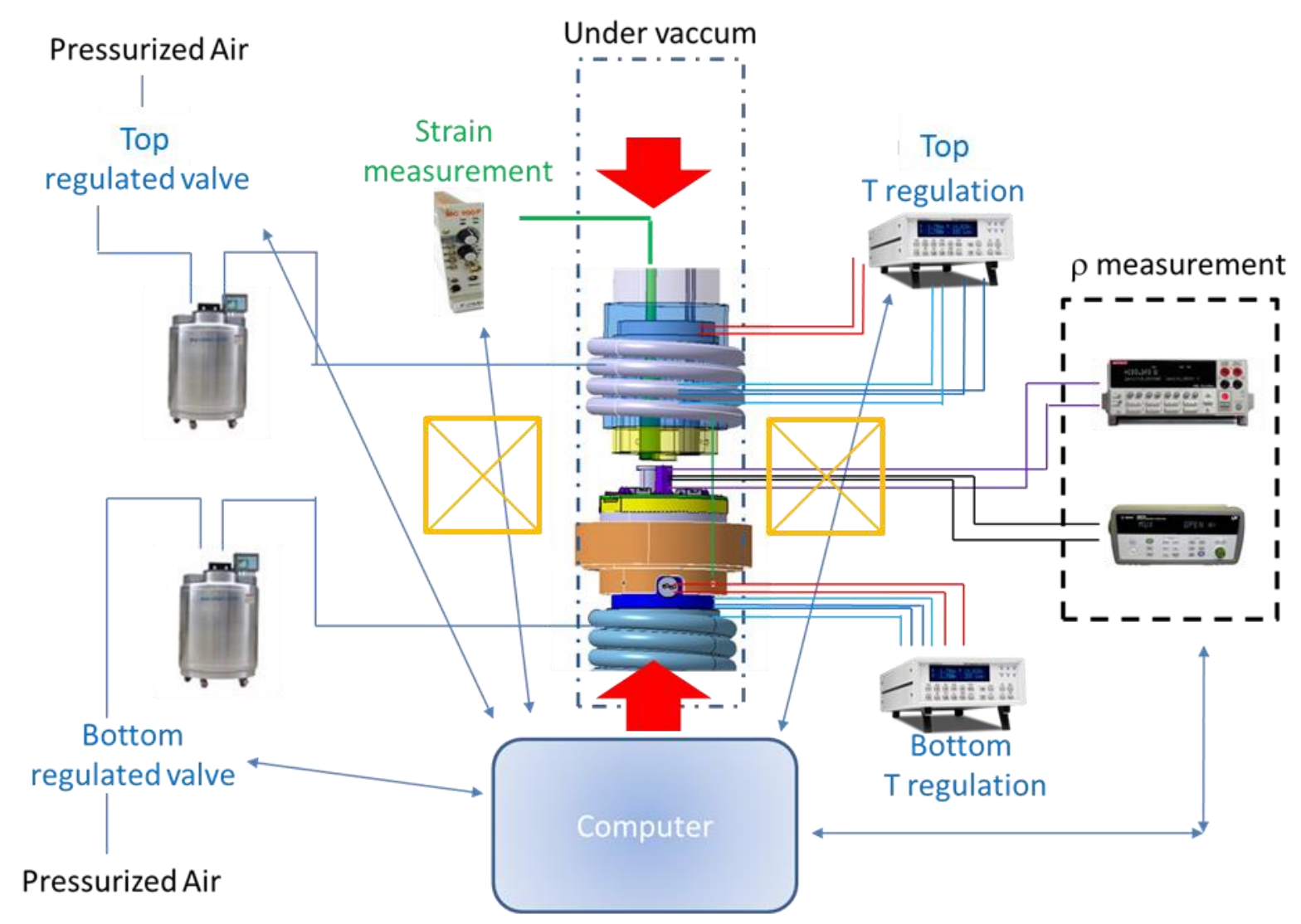

Figure 3: Synoptic scheme describing the thermal regulation of both parts of the set-up, and strain and electrical resistivity measurements. Magnetic field and stress are respectively schematized by orange squares and red arrows.

Two Pt100 $\Omega$ thermal probes are used for temperature analysis of top and bottom parts. Liquid nitrogen is used for temperature decrease below $293 \mathrm{~K}$ and is provided by a pressurized bath. Thermalization close to $77 \mathrm{~K}$ is obtained with a stainless steel capillary surrounding the copper plate. The rate is controlled by a regulated valve changing the gaz pressure in the nitrogen bath. A $50 \Omega$ heater inserted in the $\mathrm{Cu}$-Be plate ensures regulation up to $450 \mathrm{~K}$. To avoid a temperature gradient along the length of the sample, the top and bottom parts are equipped of nitrogen exchanger and heater (see figure 2). The temperature rate of the top part is controlled with nitrogen flowing using a regulating valve and the heater. As described in 
the synoptic scheme, a master/slave control was developed using LabVIEW 7 software for thermal regulation of the top and bottom parts.

Two Lakeshore 332 regulators are used to control the top and bottom temperatures in the whole $80 \mathrm{~K}-450 \mathrm{~K}$ temperature range. A thermometer glued on the sample allows accurate temperature control. Thermal history of Heusler samples is crucial for resistivity measurements. This is why regulation parameters were chosen to limit thermal oscillation (figure 4a). Indeed, such thermal variations disturb the phase transformation and the interpretation of the $\rho(\mathrm{T})$ and $\varepsilon(\mathrm{T})$ curves.

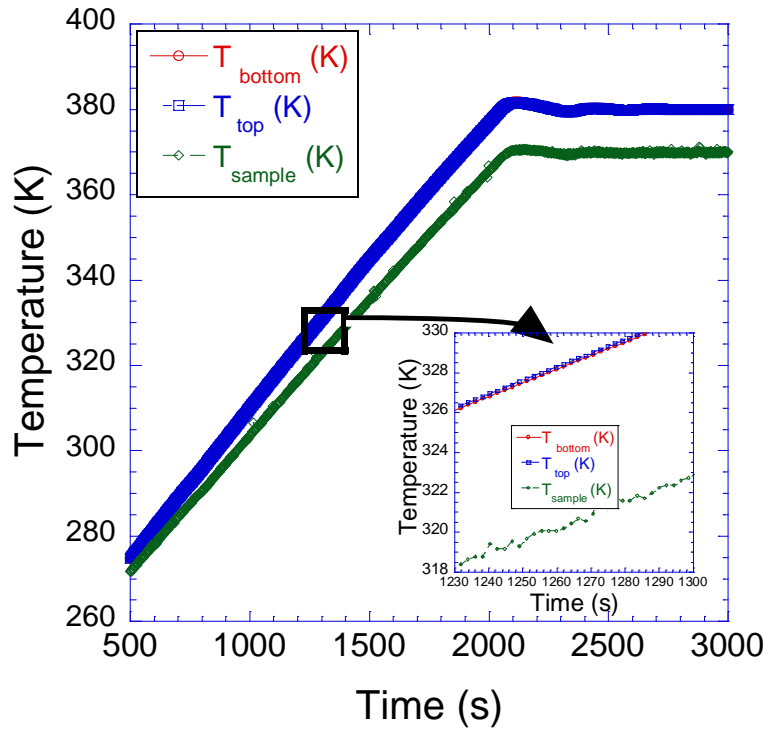

a)

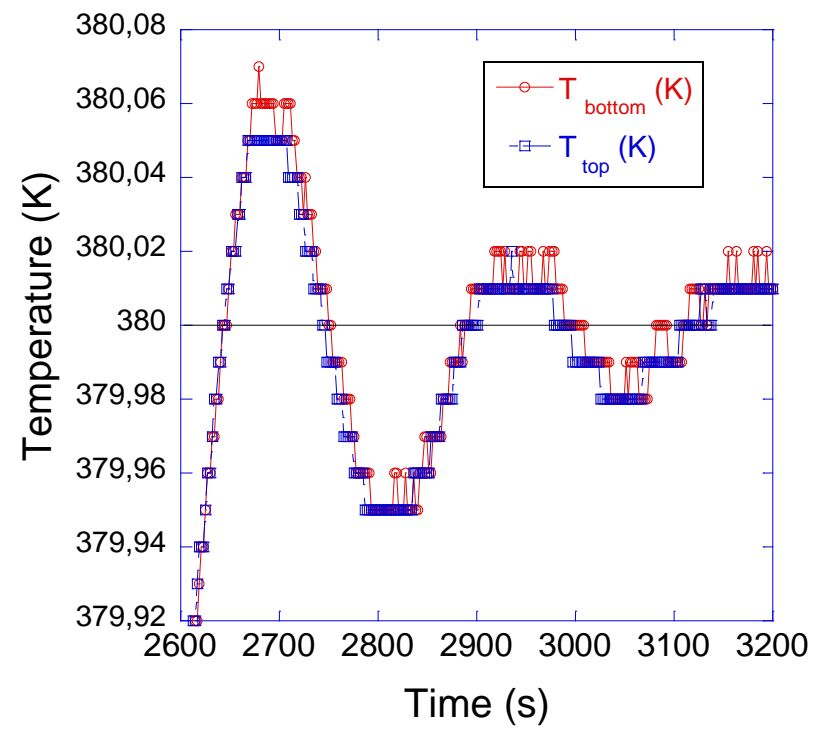

b)

Figure 4: a) Exchangers temperature versus time graphs displaying slaving of the top and bottom thermometers and temperature of the measured sample. b) Stable temperature showing small overshoot lower than $100 \mathrm{mK}$.

A proportional-integral-derivative heater/cooler mechanism minimizes thermal fluctuation during measurements at constant temperature (see figure 4b). The temperature was adjusted by changing power in the heaters and nitrogen flowing in the exchangers. Consequently 
almost one hour was necessary to reach monotonically a stable temperature without overshoot. In such experimental conditions, the temperature increase during $\rho(H, \sigma)$ and $\varepsilon(\mathrm{H}, \sigma)$ measurements could not be detected by the thermometer and was estimated lower than $100 \mathrm{mK}$.

To adjust sample temperature to the desired temperature, exchangers temperature was imposed according to the law $T_{\text {sample }}=4.36+1.087 * T_{\text {exchanger }}-0.00032 * T_{\text {exchanger }}$ (see calibration curve in figure 5).

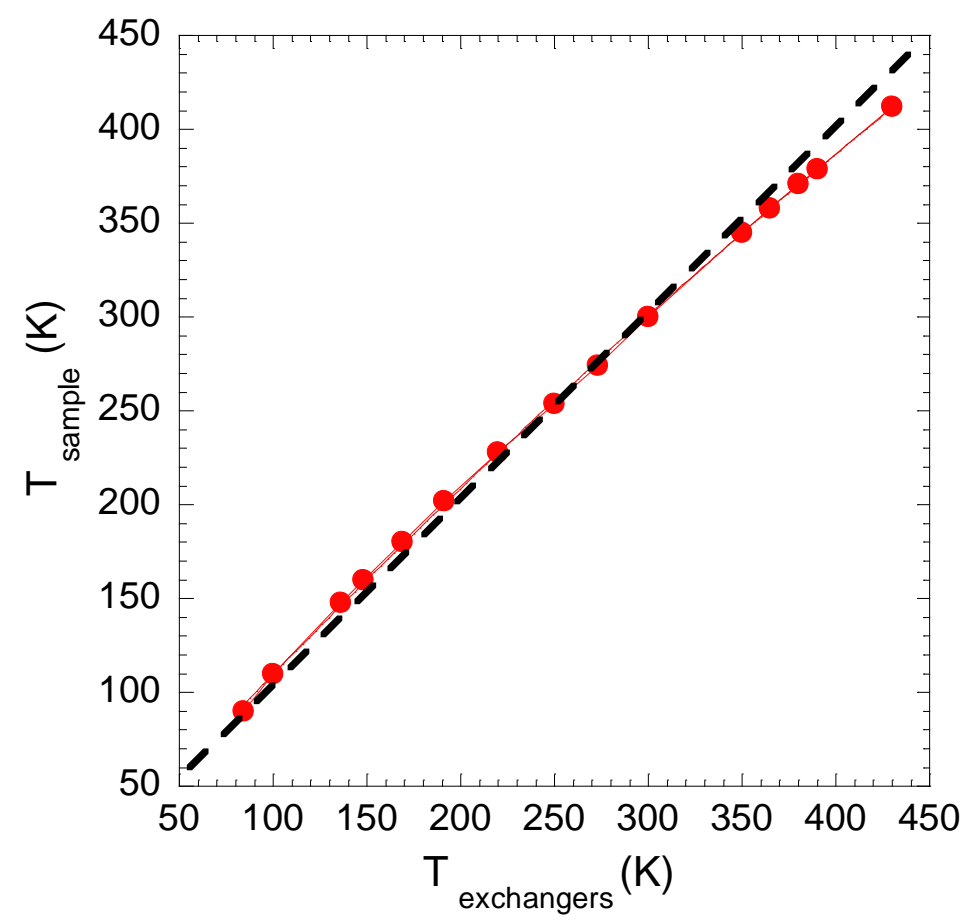

Figure 5: Sample versus exchangers calibration curve showing the law $T_{\text {sample }}=4.36+1.087 * T_{\text {exchanger }}-0.00032 * T^{2}$ exchanger.

III Multifunctional properties of Ni-Mn based Heusler materials measured using the versatile set-up

III.1 Sample preparation 
After melting of the stoichiometric alloys in a vacuum induction furnace, $\mathrm{Ni}_{45} \mathrm{Co}_{5} \mathrm{Mn}_{37.5} \mathrm{In}_{12.5}$ and $\mathrm{Ni}_{50} \mathrm{Mn}_{34.5} \mathrm{In}_{15.5}$ single crystals were grown using Bridgman method. Hard X-ray diffraction studies were used to estimate single crystal quality. The studies show that asgrown single crystals are of quite good quality with a mosaic distribution close to 15 arc minutes.

Single crystals were oriented using $\mathrm{X}$ ray backscattered Laue diffraction and cut using a diamond wire to $5 \times 1 \times 1.5 \mathrm{~mm}^{3}$ dimensions with the long length along the $<110>$ direction. $\mathrm{A} 100 \Omega$ platinum resistance was glued as thermal probe at the front of the sample. Four Ag wires soldered to the sample were used for the transport measurements as shown on figure 1.

\section{2 Results}

Table 1 summarizes the different experimental conditions (temperature, uniaxial stress and magnetic field) for the strain and electrical resistivity measurements realized on $\mathrm{Ni}_{50} \mathrm{Mn}_{34.5} \operatorname{In}_{15.5}$ and $\mathrm{Ni}_{45} \mathrm{Co}_{5} \mathrm{Mn}_{37.5} \operatorname{In}_{12.5}$ single crystals.

\begin{tabular}{|c|c|c|c|c|}
\hline \multirow{7}{*}{$\mathrm{Ni}_{50} \mathrm{Mn}_{34.5} \mathrm{In}_{15.5}$} & \multicolumn{4}{|c|}{ Strain measurements } \\
\hline & $\varepsilon(\mathrm{T})$ (fig. 7) & $90 \leq \mathrm{T} \leq 290 \mathrm{~K}$ & $0 \leq \sigma \leq 175 \mathrm{MPa}$ & $\mathrm{H}=0 \mathrm{~T}$ \\
\hline & $\begin{array}{c}\varepsilon(\mathrm{T}) \\
(\text { fig. } 9 a \text { and } b)\end{array}$ & $90 \leq \mathrm{T} \leq 290 \mathrm{~K}$ & $0 \leq \sigma \leq 55 \mathrm{MPa}$ & $\begin{array}{l}\mathrm{H}=0 \mathrm{~T} \\
\mathrm{H}=2 \mathrm{~T}\end{array}$ \\
\hline & $\begin{array}{c}\sigma(\varepsilon) \\
\text { (fig. 9c) } \\
\end{array}$ & $\mathrm{T}=220 \mathrm{~K}$ & $0 \leq \sigma \leq 55 \mathrm{MPa}$ & $\begin{array}{l}\mathrm{H}=0 \mathrm{~T} \\
\mathrm{H}=2 \mathrm{~T}\end{array}$ \\
\hline & & Electrical resisti & ty measurements & \\
\hline & $\rho(\mathrm{T})($ fig. $8 a)$ & $150 \leq \mathrm{T} \leq 300 \mathrm{~K}$ & $110 \leq \sigma \leq 250 \mathrm{MPa}$ & $\mathrm{H}=0 \mathrm{~T}$ \\
\hline & $\rho(\mathrm{T})($ fig. $8 b)$ & $90 \leq \mathrm{T} \leq 420 \mathrm{~K}$ & $\sigma=50 \mathrm{MPa}$ & $0 \leq \mathrm{H} \leq 6 \mathrm{~T}$ \\
\hline
\end{tabular}

\begin{tabular}{|c|c|c|c|c|}
\hline \multirow{4}{*}{$\mathbf{N i}_{\mathbf{4 5}} \mathbf{C o}_{\mathbf{5}} \mathbf{M n}_{\mathbf{3 7 . 5}} \mathbf{I n}_{\mathbf{1 2 . 5}}$} & \multicolumn{4}{|c|}{ Strain measurements } \\
\cline { 2 - 5 } & $\begin{array}{c}\varepsilon(\mathrm{T}) \\
(\text { fig. } 6 a, b, c)\end{array}$ & $290 \leq \mathrm{T} \leq 440 \mathrm{~K}$ & $0 \leq \sigma \leq 125 \mathrm{MPa}$ & $\begin{array}{c}\mathrm{H}=0 \mathrm{~T} \\
\mathrm{H}=2 \mathrm{~T} \\
\mathrm{H}=4 \mathrm{~T}\end{array}$ \\
\cline { 2 - 5 } & $\begin{array}{c}\varepsilon(\mathrm{T}) \\
\text { fig. } 10 a)\end{array}$ & $300 \leq \mathrm{T} \leq 400 \mathrm{~K}$ & $\begin{array}{c}\sigma=20 \mathrm{MPa} \\
\sigma=50 \mathrm{MPa}\end{array}$ & $2 \leq \mathrm{H} \leq 8 \mathrm{~T}$ \\
\cline { 2 - 5 } & $\varepsilon(\mathrm{H})$ & $\mathrm{T}=350 \mathrm{~K}$ & $0 \leq \sigma \leq 40 \mathrm{MPa}$ & $0 \leq \mathrm{H} \leq 8 \mathrm{~T}$ \\
\cline { 2 - 5 }
\end{tabular}




\begin{tabular}{|l|c|c|c|}
\hline & (fig. 10b) & $\mathrm{T}=360 \mathrm{~K}$ & $\sigma=60 \mathrm{MPa}$ \\
& & $\mathrm{T}=370 \mathrm{~K}$ & $40 \leq \sigma \leq 60 \mathrm{MPa}$ \\
& & $\mathrm{T}=380 \mathrm{~K}$ & $\sigma=60 \mathrm{MPa}$
\end{tabular}

Table 1: Experimental conditions (temperature, uniaxial stress and magnetic field) for the strain and electrical resistivity measurements realized on $\mathrm{Ni}_{50} \mathrm{Mn}_{34.5} \mathrm{In}_{15.5}$ and $\mathrm{Ni}_{45} \mathrm{Co}_{5} \mathrm{Mn}_{37.5} \mathrm{In}_{12.5}$ single crystals.

It should be noticed that the stress level has been limited to $250 \mathrm{MPa}$ in view to reduce sample breaking even if the device is able to support uniaxial stress up to $1 \mathrm{GPa}$. Indeed, Ni-Mn based Heusler materials have shown high brittleness reinforced by a high ratio length / section $(5 / 1.5)$

\section{-Phase transformation}

The transformation temperatures (see inset of figure 6a) are the martensitic start Ms, the martensitic finish Mf, the austenitic start As, the austenitic finish Af. These temperatures are determined as the intersection of linear regions for $\rho$-T and $\varepsilon$-T curves at different magnetic fields and pressures. 


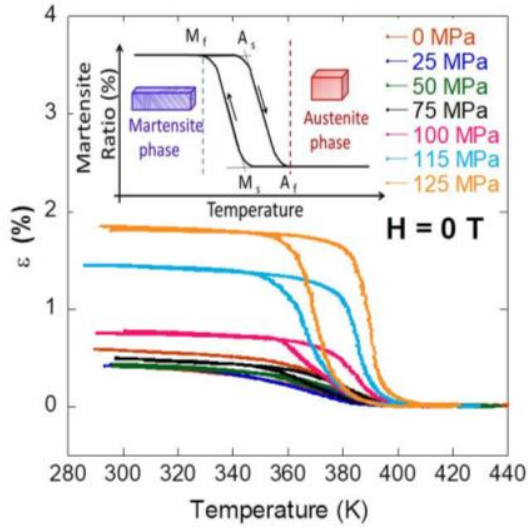

a)

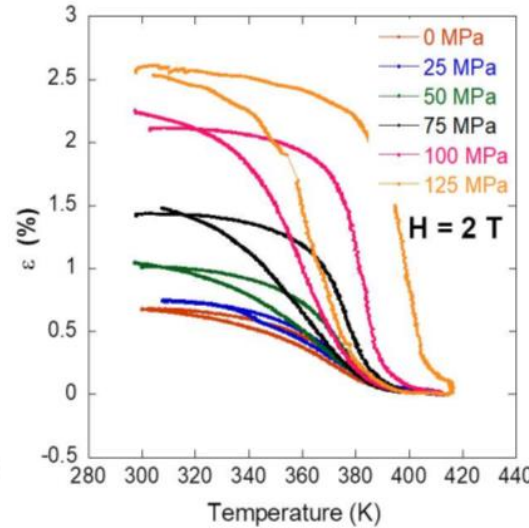

b)

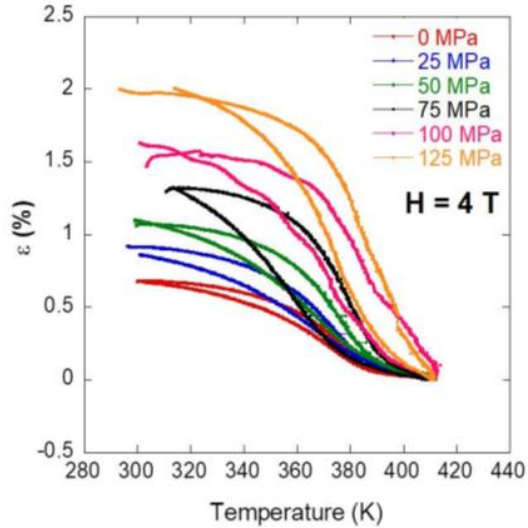

c)

Figure 6: Strain as a function of temperature (E-T curves) measured on $\mathrm{Ni}_{45} \mathrm{Co}_{5} \mathrm{Mn}_{37.5} \mathrm{In}_{12.5}$ single crystal during cooling and heating under different constant uniaxial stress levels for $H=0 T(a), 2 T(b)$ and $4 T(c)$.

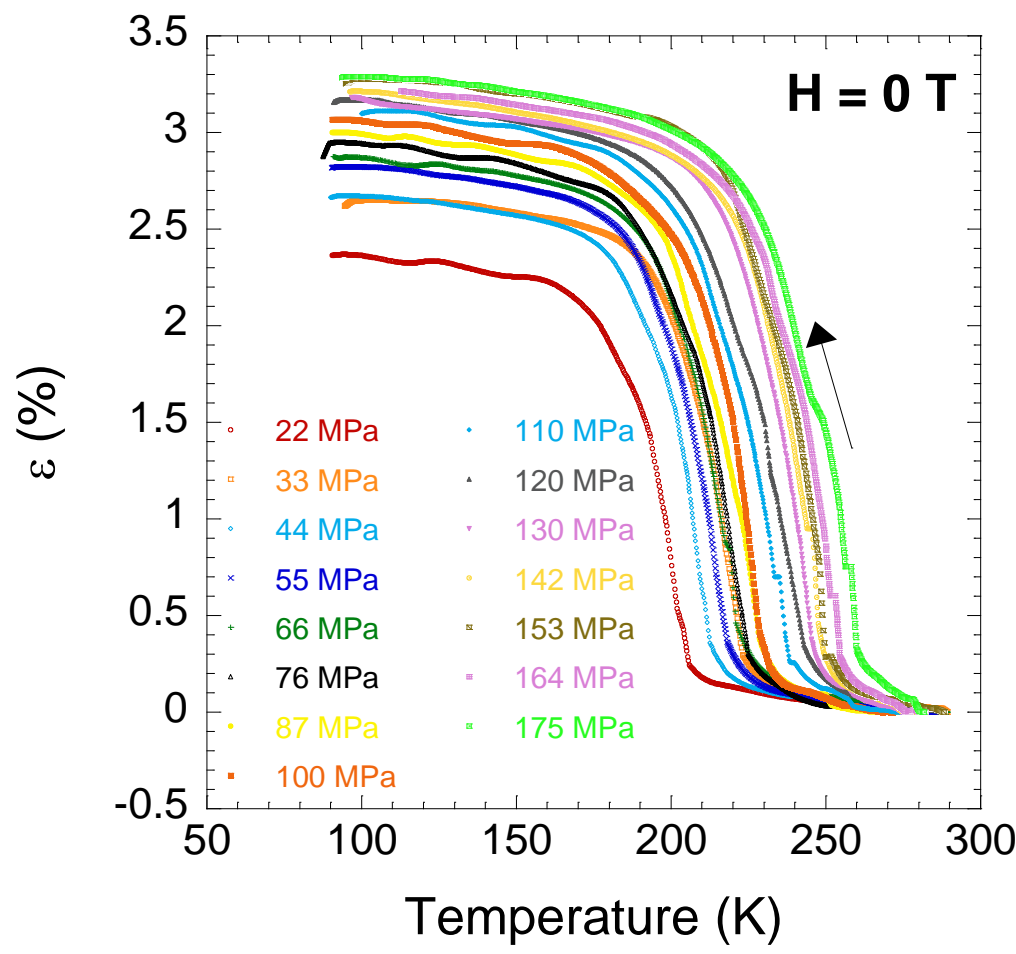

Figure 7: Strain as a function of temperature ( $\varepsilon-T$ curves) measured on $\mathrm{Ni}_{50} \mathrm{Mn}_{34.5} \mathrm{In}_{15.5}$ single crystal during cooling under different constant uniaxial stress levels for $H=0 T$. 
Two single crystals with $\mathrm{Ni}_{45} \mathrm{Co}_{5} \mathrm{Mn}_{37.5} \mathrm{In}_{12.5}$ (figure 6) and $\mathrm{Ni}_{50} \mathrm{Mn}_{34.5} \mathrm{In}_{15.5}$ (figure 7) respective composition were measured using our versatile device. To eliminate the phases arrest phenomenon under external fields, a thermal cycle from the martensite state to the austenite state was realized in zero magnetic field and zero stress prior to all the strain temperature measurements. In these conditions, the sample is virginized before applying different magnetic fields and stresses.

Figure 6 shows the strain measurements obtained on $\mathrm{Ni}_{45} \mathrm{Co}_{5} \mathrm{Mn}_{37.5} \mathrm{In}_{12.5}$ single crystal for cooling and heating runs under different constant uniaxial stress levels for $\mathrm{H}=0 \mathrm{~T}$ (figure $6 \mathrm{a}$ ), $2 \mathrm{~T}$ (figure $6 \mathrm{~b}$ ) and $4 \mathrm{~T}$ (figure $6 \mathrm{c}$ ). The strain is calculated by $\varepsilon=\left(1-1_{0}\right) / 1_{0}=\Delta \mathrm{l} / 1_{0}$ where 1 is the length which is parallel to the stress direction and $1_{0}$ is the reference length at the temperature for which the sample is in the austenite state (for example $420 \mathrm{~K}$ in figure $6 \mathrm{a}$ ). During cooling and heating, the first-order austenite-martensite phase transition occurs as shown schematically in the inset of figure 6a. The phase transformation leads to a strain variation which spreads over temperature intervals decreasing with the applied stress. The transition temperature values $\mathrm{T}_{\mathrm{A}-\mathrm{M}}=354 \mathrm{~K}$ and $\mathrm{T}_{\mathrm{M}-\mathrm{A}}=363 \mathrm{~K}$ for respectively the forward and reverse phase transition can be determined with the inflection points of the strain curves. For a given magnetic field, the transformation temperature varies linearly with the applied stress. The $\mathrm{dT}_{\mathrm{M}-\mathrm{A}} / \mathrm{d} \sigma$ and $\mathrm{dT}_{\mathrm{A}-\mathrm{M}} / \mathrm{d} \sigma$ values are close to $0.2 \mathrm{~K} \mathrm{MPa}^{-1}$ whatever the applied magnetic field. In addition, the strain change of the forward and the reverse transition increases with the applied stress up to $125 \mathrm{MPa}$.

The highest strain was measured for $2 \mathrm{~T}$ and $125 \mathrm{MPa}$, with a value close to $2.5 \%$. For a stress of $125 \mathrm{MPa}$ and a field of $4 \mathrm{~T}$, it is surprising to observe a lower strain close to $2 \%$. Figure S2 (in supplementary information) shows that, under $50 \mathrm{MPa}$, the highest strain for $2 \mathrm{~T}$ and $4 \mathrm{~T}$ is comparable. A difference in strain is clearly visible between $2 \mathrm{~T}$ and $4 \mathrm{~T}$ above $75 \mathrm{MPa}$ and is reduced for a $125 \mathrm{MPa}$ stress. This behavior could be due to different 
directions of martensite variants rearrangements induced by magnetic field and stress. Because of their antagonist effects, it is possible that the simultaneous application of magnetic field and stress induces rearrangements in various directions yielding lower strain intensity. In the future, this surprising result will be further investigated with specific experiments in this range of magnetic field and stress so as to understand the role of the magnetic field and stress on the martensite variants rearrangements.

It should also be noticed that, for a given stress, forward and reverse transformation temperatures $\mathrm{T}_{\mathrm{M}-\mathrm{A}}$ and $\mathrm{T}_{\mathrm{A}-\mathrm{M}}$ decrease of about $6 \mathrm{~K}$ by applying a magnetic field of $4 \mathrm{~T}$. This decrease is due to the magnetic state of the austenite and martensite phases which are respectively ferromagnetic and antiferromagnetic ${ }^{40}$.

Figure 7 shows the strain as a function of temperature measured on $\mathrm{Ni}_{50} \mathrm{Mn}_{34.5} \operatorname{In}_{15.5}$ single crystal during cooling under different constant uniaxial stress levels for $\mathrm{H}=0 \mathrm{~T}$. For this composition, the temperature of the forward transition $\mathrm{T}_{\mathrm{A}-\mathrm{M}}$ is below room temperature, close to $195 \mathrm{~K}$. T A-M varies linearly with the applied stress with a $\mathrm{dT}_{\mathrm{A}-\mathrm{M}} / \mathrm{d} \sigma$ value of $0.32 \mathrm{~K} \mathrm{MPa}^{-1}$.

For a stress level of at least $150 \mathrm{MPa}$, a maximum strain of $3.3 \%$ is obtained for this sample. 


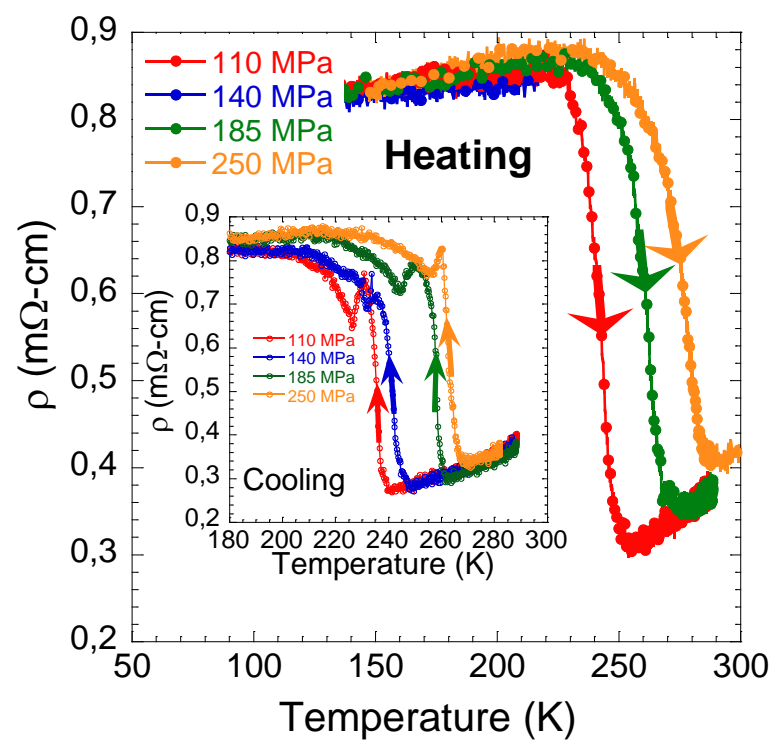

a)

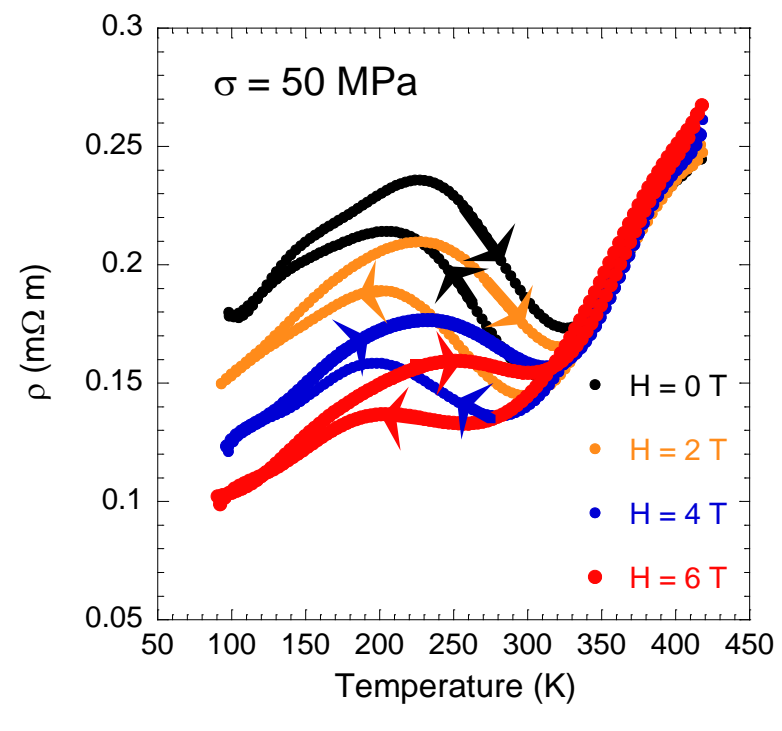

b)

Figure 8: Temperature dependence of the electrical resistivity under uniaxial stress varying between $110 \mathrm{MPa}$ and $250 \mathrm{MPa}$ (a) and under magnetic field varying between $0 \mathrm{~T}$ and $6 \mathrm{~T}$ (b) for a $\mathrm{Ni}_{50} \mathrm{Mn}_{34.5} \mathrm{In}_{15.5}$ single crystal.

Electrical resistivity and strain loops on $\mathrm{Ni}_{50} \mathrm{Mn}_{34.5} \mathrm{In}_{15.5}$ single crystal are presented in figure 8 , as a function of temperature under uniaxial stress (figure 8a) and magnetic field (figure 8b). During magnetic field application, transformation from the martensite to austenite phase shifts towards low temperatures, whereas for pressure application the transformation shifts towards high temperatures. It should be noticed that, in the cooling branch of the $\rho$ (T) curves under stress (see inset in figure 8a), a small peak in the transformation temperature window is present, certainly due to additional internal stress in the single crystal. The isothermal uniaxial stress and magnetic field dependence of the resistivity can also be studied with our versatile set-up. Large magnetoresistance MR and piezoresistance PR, defined as $[\rho(\mathrm{H}, \sigma)-\rho(0)] / \rho(0)$ can be obtained in such Heusler materials as it was already demonstrated in previous works ${ }^{29,34-38}$. 


\section{-Superelasticity under magnetic field and magnetostress}

The superelastic response exhibits a shift to higher stress levels with increasing magnetic field magnitudes. An example is shown in figures $9 \mathrm{a}$ and $9 \mathrm{~b}$ for a $\mathrm{Ni}_{50} \mathrm{Mn}_{34.5} \operatorname{In}_{15.5}$ crystal measured with a uniaxial stress applied along the $\langle 110>$ direction under $0 \mathrm{~T}$ (figure $9 \mathrm{a}$ ) and $2 \mathrm{~T}$ (figure $9 \mathrm{~b})$. The magnitude of the shift is determined at $2 \%$. As shown in figure $9 \mathrm{c}$, the sample exhibits approximately $10 \mathrm{MPa}$ magnetostress under $2 \mathrm{~T}$ which is comparable to the value obtained in Ni-Co-Mn-In ${ }^{55}$ and in other MSMAs (2 - 8 MPa for Ni-Mn-Ga alloys $)^{56}$.

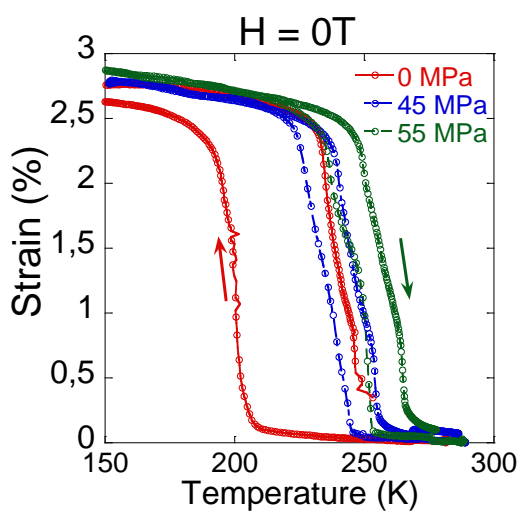

a)

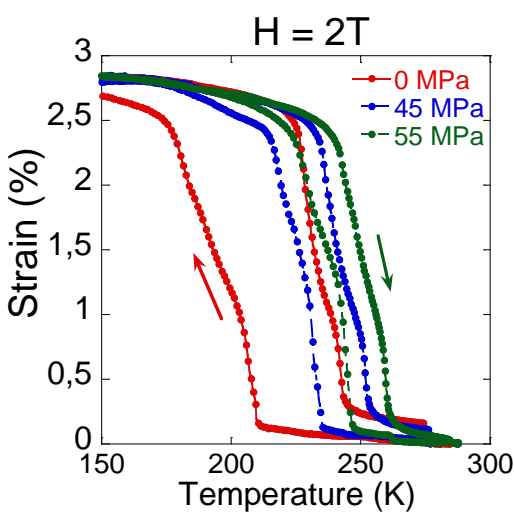

b)

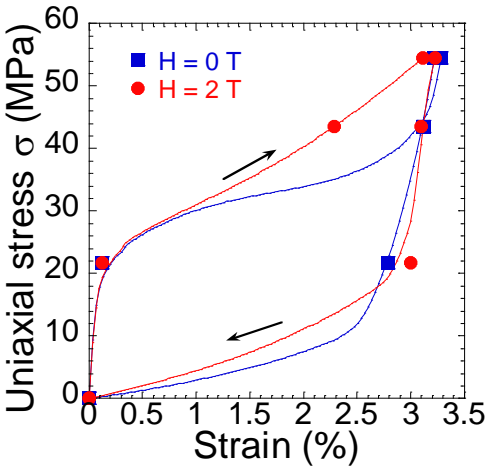

c)

Figure 9: Strain as a function of temperature (E-T curves) measured during cooling and heating under different constant uniaxial stress levels for $\mathrm{H}=0$ (a) and $\mathrm{H}=2 \mathrm{~T}(\mathrm{~b})$. Effect of the magnetic field on stress - strain response at $220 \mathrm{~K}(\mathrm{c})$.

\section{$\underline{\text {-Strain under magnetic field }}$}

Figure 10a shows the strain versus temperature increase for different magnetic fields in a $\mathrm{Ni}_{45} \mathrm{Co}_{5} \mathrm{Mn}_{37.5} \mathrm{In}_{12.5}$ single crystal uniaxially compressed under 20 and $50 \mathrm{MPa}$. Curves $\Delta \varepsilon(\mathrm{H})=\varepsilon(8 \mathrm{~T})-\varepsilon(\mathrm{H})$ for different stresses and temperatures can also be obtained by varying the magnetic field at constant temperature and stress (figure 10b). In these conditions, phase transformation can be induced by a magnetic field in Ni-Mn alloy materials. As the 
applied field decreases, single magnetic austenite domain transforms into multi martensite domain and vice versa. This phenomenon is named stress-assisted field-induced phase transformation and is analogous to stress-assisted thermally-induced phase transformation (figure 10a). The strain variations $\Delta \varepsilon(\mathrm{H})$ obtained under magnetic fields are lower than the $1.5 \%$ expected value because the maximum magnetic field of $8 \mathrm{~T}$ is not high enough to induce total phase transformation in our single crystal sample. The variation $\Delta \varepsilon(\mathrm{H})$ even becomes negligible for temperature lower or equal to $360 \mathrm{~K}$ for which magnetic field of $8 \mathrm{~T}$ is too low for the martensite to austenite phase transformation.

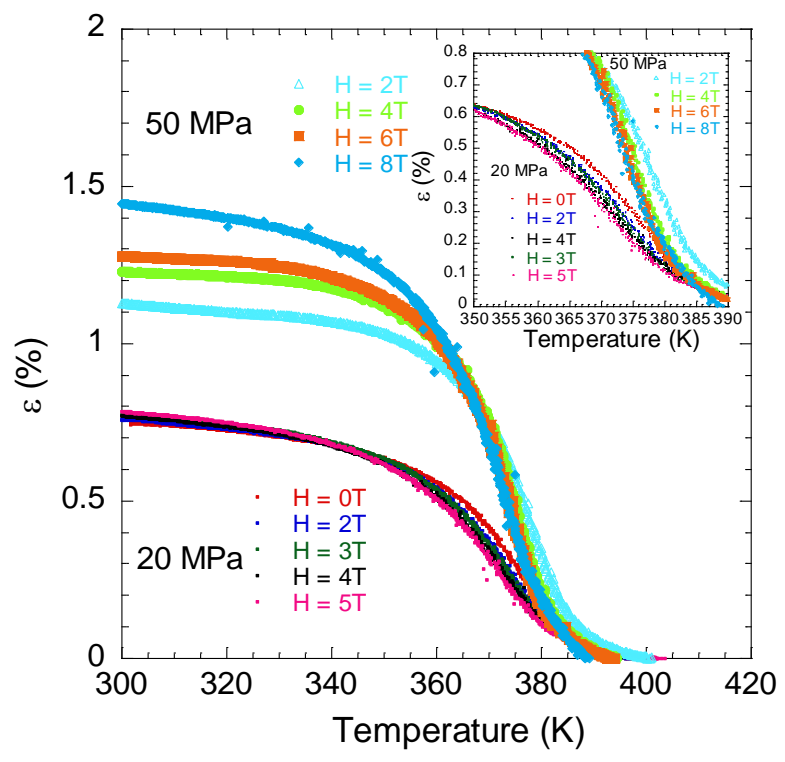

a)

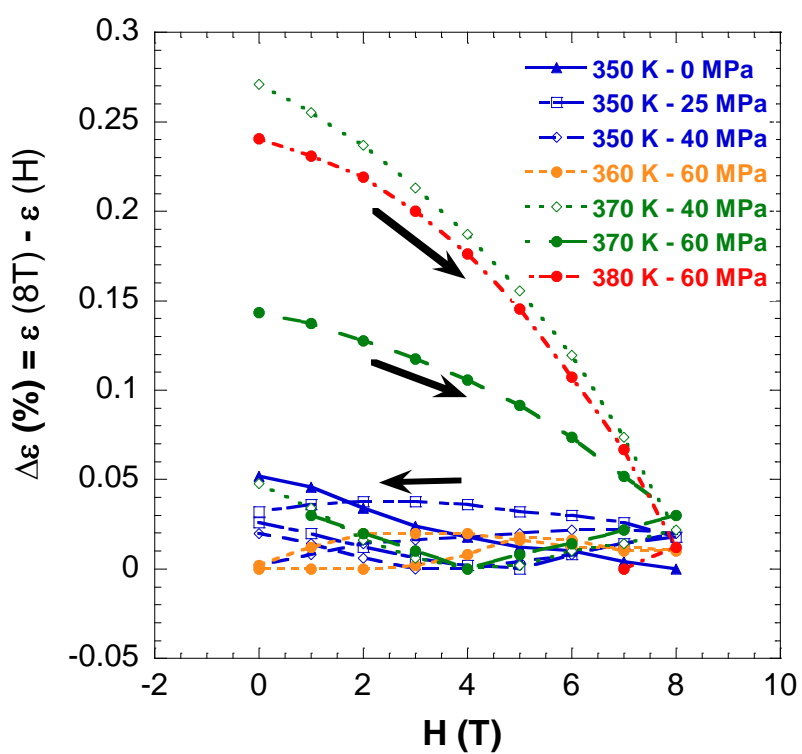

b)

Figure 10 : a) Strain versus temperature increase in a $\mathrm{Ni}_{45} \mathrm{Co}_{5} \mathrm{Mn}_{37.5} \mathrm{In}_{12.5}$ single crystal uniaxially compressed under 20 and $50 \mathrm{MPa}$. In inset a magnification of the $\varepsilon(T)$ curves shows the decrease of the transformation temperature under magnetic field increase. b) Magnetic field induced strain variation in the single crystal uniaxially compressed under 0 , 25 and $40 \mathrm{MPa}$ at $350 \mathrm{~K}$ (blue curves), under $60 \mathrm{MPa}$ at $360 \mathrm{~K}$ (orange curve), under 40 and $60 \mathrm{MPa}$ at $370 \mathrm{~K}$ (green curves) and under $60 \mathrm{MPa}$ at $380 \mathrm{~K}$ (red curve). 


\section{$\underline{\text { Elastocaloric effect }}$}

The entropy variation $\Delta \mathrm{S}$ was estimated numerically from the $\varepsilon$ - $\mathrm{T}$ curves displayed in figures 6 and 7 according to the following relation:

$$
\Delta S(T, \sigma)=\mathcal{U}_{0} \int_{0}^{\sigma}\left(\frac{\partial \varepsilon}{\partial T}\right)_{\sigma} d \sigma
$$

where $\boldsymbol{U}_{0}$ is the specific volume ${ }^{57}$. The estimated $\Delta \mathrm{S}$ for different stress levels is illustrated as a function of temperature in figures 11 and 12 for respectively $\mathrm{Ni}_{45} \mathrm{Co}_{5} \mathrm{Mn}_{37.5} \operatorname{In}_{12.5}$ and $\mathrm{Ni}_{50} \mathrm{Mn}_{34.5} \mathrm{In}_{15.5}$ single crystals. For $\mathrm{Ni}_{45} \mathrm{Co}_{5} \mathrm{Mn}_{37.5} \mathrm{In}_{12.5}$ sample, $\Delta \mathrm{S}$ varies between 3.5 and $6.5 \mathrm{~J} \mathrm{~kg}^{-1} \mathrm{~K}^{-1}$ at $380 \mathrm{~K}$ under a stress of $126 \mathrm{MPa}$ and a magnetic field between 0 and $4 \mathrm{~T}$ (figures $11 \mathrm{a}, 11 \mathrm{~b}$ and $11 \mathrm{c}$ ). For a stress of $126 \mathrm{MPa}, \Delta \mathrm{S}$ is $6.5 \mathrm{~J} \mathrm{~kg}^{-1} \mathrm{~K}^{-1}$ for $2 \mathrm{~T}$ whereas it reaches $4.5 \mathrm{~J} \mathrm{~kg}^{-1} \mathrm{~K}^{-1}$ for $4 \mathrm{~T}$. This trend is directly correlated to the strain-temperature curves determined under magnetic field and stress (figures $6 \mathrm{a}, \mathrm{b}$ and c). As explained before, the lower strain obtained at $4 \mathrm{~T}$ can be due to various variants rearrangement induced by magnetic field and stress.

Actually, this is a low stress-induced entropy change, which corresponds to $25 \%$ of the maximum attainable value, i.e. the transformation entropy change $\Delta S_{\mathrm{tr}}=30 \mathrm{~J} \mathrm{~kg}^{-1} \mathrm{~K}^{-1}$. This is due to the fact that a $126 \mathrm{MPa}$ uniaxial pressure is not capable of inducing a complete martensitic transformation at this temperature for this single crystal. For $\mathrm{Ni}_{50} \mathrm{Mn}_{34.5} \operatorname{In}_{15.5}$ sample, $\Delta \mathrm{S}$ is close to $12.5 \mathrm{~J} \mathrm{~kg}^{-1} \mathrm{~K}^{-1}$ at $220 \mathrm{~K}$ under a stress of $176 \mathrm{MPa}$ (figure 12). The maximum $\Delta S$ value $\left.|\Delta S|_{\text {Max }}\right)$ obtained under each stress level, was plotted as a function of applied stress in the insets of figure 12. This is a quite large stress-induced entropy change, which corresponds to $86 \%$ of the maximum attainable value, i.e. the transformation entropy change $\Delta \mathrm{S}_{\mathrm{tr}}=14.5 \mathrm{~J} \mathrm{~kg}^{-1} \mathrm{~K}^{-1}$. 


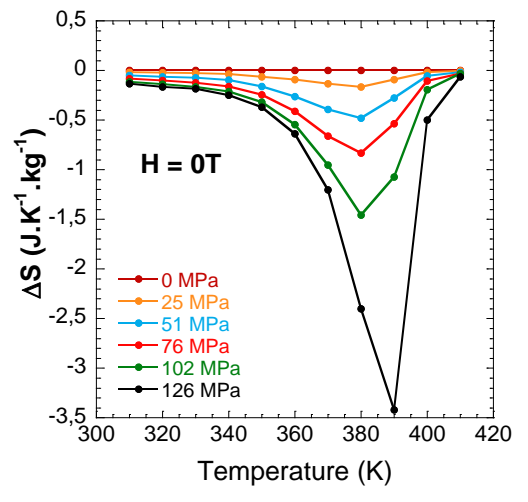

a)

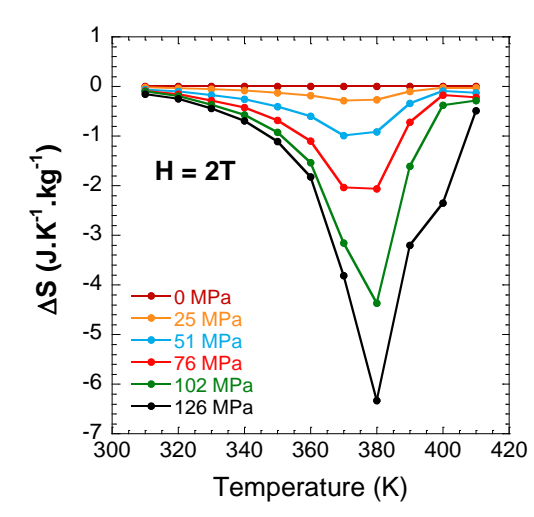

b)

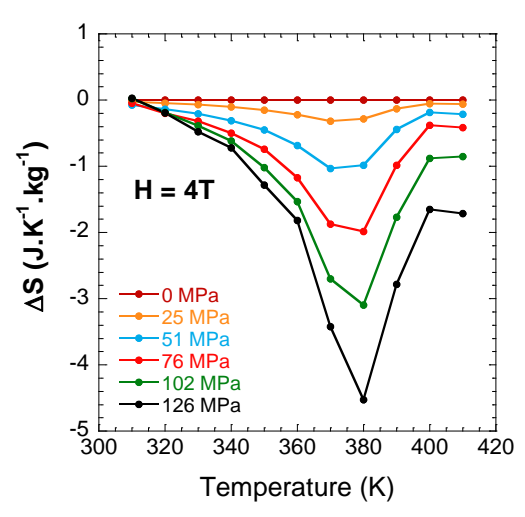

c)

Figure 11 : Temperature dependence of stress-induced entropy change $\Delta S$ under different stress levels calculated from the $\varepsilon-T$ curves measured on $\mathrm{Ni}_{45} \mathrm{Co}_{5} \mathrm{Mn}_{37.5} \mathrm{In}_{12.5}$ single crystal during cooling and heating under different constant uniaxial stress levels for $H=0 T, 2 T$ and $4 T$ (figure 6).

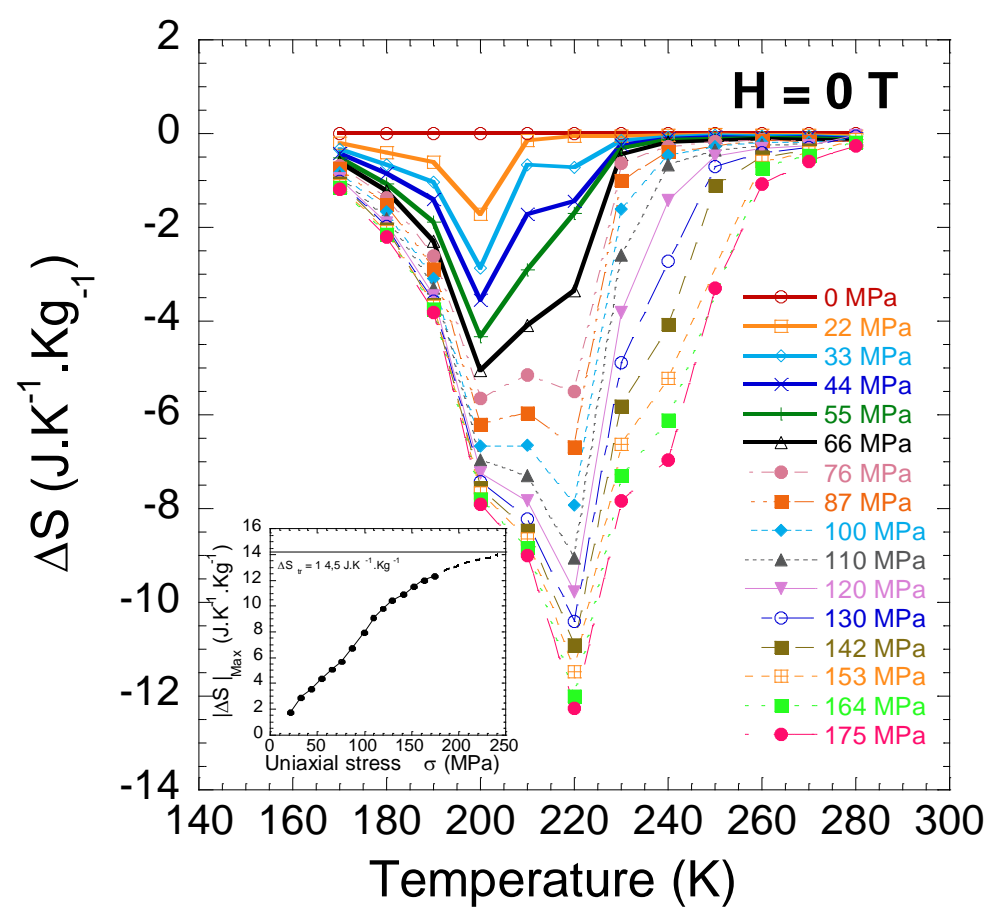

Figure 12 : Temperature dependence of stress-induced entropy change $\Delta S$ under different stress levels calculated from the $\varepsilon-T$ curves measured on $N i_{50} M_{34.5} I_{15.5}$ single crystal during cooling and heating under different constant uniaxial stress levels for $\mathrm{H}=0 \mathrm{~T}$ 
(figure 7). The inset shows the maximum $\Delta S$ value $\left(|\Delta S|_{\text {Max }}\right)$ obtained under each stress level.

\section{Conclusions}

A versatile set-up for electrical resistivity and strain measurements under continuous uniaxial pressure, temperature and magnetic field is described in this paper. This device allows the study of several interesting properties of materials showing hysteretic processes during martensitic transformation. The transport resistivity and strain set-up works in a $80 \mathrm{~K}-450 \mathrm{~K}$ temperature range, in magnetic fields up to $8 \mathrm{~T}$ and under a maximum uniaxial stress of $1 \mathrm{GPa}$. Heusler Ni-(Co)-Mn-In single crystals were measured using the described device to show its versatility.

Phase transformation, magnetoresistance, piezoresistance, magnetic field phase transformation, superelasticity under magnetic field and magnetostress can indeed be studied with our versatile device.

Elastocaloric cooling capacity can also be estimated. As an example, stress-induced entropy changes $\Delta \mathrm{S}$ were estimated numerically from the $\varepsilon$ - $\mathrm{T}$ curves for $\mathrm{Ni}_{45} \mathrm{Co}_{5} \mathrm{Mn}_{37.5} \mathrm{In}_{12.5}$ and $\mathrm{Ni}_{50} \mathrm{Mn}_{34.5} \mathrm{In}_{15.5}$ single crystals. A significant stress-induced entropy change of $12.5 \mathrm{~J} \mathrm{~kg}^{-1} \mathrm{~K}^{-1}$, corresponding to $86 \%$ of the transformation entropy change, was obtained in the $\mathrm{Ni}_{50} \mathrm{Mn}_{34.5} \mathrm{In}_{15.5}$ single crystal.

We believe that this type of device will be of great help to study materials with coupled properties in magnetic, elastic, and thermal domains. The work presented here is complementary to the studies focused on the modeling of Thermo-Electro-MagnetoMechanical behavior for these functional materials. 


\section{Acknowledgements:}

The authors thank L. Hirsinger from the FEMTO-ST Institute for discussions on the strainstress design and the SERAS service of the Neel Institute for the electroerosion cutting of several parts of the set-up.

The authors would also like to thank Région Auvergne Rhône-Alpes for funding Hugo Dufour’s grant ( $\mathrm{N}^{\circ} 18$ 000401001-10688).

Data availability statement: The datasets generated and/or analyzed during the current study are available from the corresponding author on reasonable request. 


\section{References :}

${ }^{1}$ H. E. Karaca, I. Karaman, B. Basaran, Y. J. Chumlyakov, H. J. Maier, Acta Mater. 54, 233 (2006).

${ }^{2}$ J. A. Monroe, I. Karaman, B. Basaran, W. Ito, R. Y. Umetsu, R. Kainuma, K. Koyama, Y. I. Chumlyakov, Acta Mater. 60, 6883 (2012).

${ }^{3}$ N. M. Bruno, I. Karaman, J. H. Ross Jr., Y. I. Chumlyakov, Rev. Sci. Instrum. 86, 113902 (2015).

${ }^{4}$ P. Müllner,V. A. Chernenko, G.Kostorz, J. Appl. Phys. 95, 1531 (2004).

${ }^{5}$ K. Haldar, D. C. Lagoudas, I. Karaman, J. Mech. Phys. Solids 69, 33 (2014).

${ }^{6}$ N. M. Bruno, C. Ciocanel, H. P. Feigenbaum, A.Waldauer, Smart Mater. Struct. 21, 094018 (2012).

${ }^{7}$ B. Kiefer, H. E. Karaca, D. C. Lagoudas, I. Karaman, J. Magn. Magn. Mater. 312, 164 (2007).

${ }^{8}$ L. Hirsinger, Physica status solidi (c) 11, 1016 (2014).

${ }^{9}$ U. Welp, M. Grimsditch, S. Fleshler, W. Nessel, J. Downey, G. W. Crabtree, J. Guimpel, Phys. Rev. Lett. 69, 2130 (1992).

${ }^{10}$ S. Arumugam, N. Mori, N. Takeshita, H. Takashima, T. Noda, H. Eisaki, S. Uchida, Phys. Rev. Lett. 88, 247001 (2002).

${ }^{11}$ J. M. Tranquada, J. D. Axe, N. Ichikawa, A. R. Moodenbaugh, Y. Nakamura, S. Uchida, Phys. Rev. Lett. 78, 338 (1997).

${ }^{12}$ H. Takahashi, N. Mori, in Studies of High Temperature Superconductors, edited by A. V. Narlikar. Nova Science Publishers, 16, 1 (1996).

${ }^{13}$ D. Braithwaite, G. Chouteau, G. Martinez, Meas. Sci. Technol. 1, 1347 (1990).

${ }^{14}$ R. Movshovich, T. Graf, D. Mandrus, J. D. Thompson, J. L. Smith, Z. Fisk, Phys. Rev. B 53, $8241(1996)$. 
${ }^{15}$ B. Bellarbi, A. Benoit, D. Jaccard, J.-M. Mignot, H. F. Braun, Phys. Rev. B 30, 1182 (1984).

${ }^{16}$ D. Jaccard, K. Beehnia, J. Sierro, Phys. Rev. Lett. A, 163, 475 (1992).

${ }^{17}$ S. S. Saxena, P. Agarwal, K. Ahilan, F. M. Grosche, R. K. W. Haselwimmer, M. J. Steiner, E. Pugh, I. R. Walker, S. R. Julian, P. Monthoux, G. G. Lonzarich, A. Huxley, I. Sheikin, D. Braithwaite, J. Flouquet, Nature 406, 587 (2000).

${ }^{18}$ V. Markovich, E. Rozenberg, G. Gorodetsky, M. Greenblatt, W. H. McCarroll, Phys. Rev. B 63, 054423 (2001).

${ }^{19}$ M. Ishizuka, Y. Kai, R. Akimoto, M. Kobayahshi, K. Amaya, S. Endo, J. Magn. Magn. Mater. 166, 211 (1997).

${ }^{20}$ T. Adachi, H. Tanaka, H. Kobayahshi, T. Miyazaki, Rev. Sci. Instrum. 72, 2358 (2001).

${ }^{21}$ A. Kurita, M. Miyashita, H. Taniguchi, K. Satoh, M. Tamura, R. Kato, M. Hedo, Y. Watoko, Physica C 388, 603 (2003).

${ }^{22}$ G. Jones, D. J. Dunstan, Rev. Sci. Instrum. 67, 489 (1996).

${ }^{23}$ A. R. Adams, C. Pickering, P. J. Vinson, J. Phys. E 13, 1331 (1980).

${ }^{24}$ S. Arumugam, K. Mydeen, M. Kumaresa Vanji, N. Mori, Rev. Sci. Instrum. 76, 083904 (2005).

${ }^{25}$ A. Jayaraman, A. R. Hutson, J. H. McFee, A. S. Coriell, R. G. Maines, Rev. Sci. Instrum. 38, 44 (1967).

${ }^{26}$ N. Zhang, W. Ding, Z. Guo, D. Zing, Y. Du, G. Li, Y. Zheng, Chin. Phys. Lett. 13, 870 (1996).

${ }^{27}$ Y Echizen, K Umeo, T Igaue, T Takabatake, J. Phys.: Condens. Matter 14, 5145 (2002).

${ }^{28}$ K. Bakker, A. de Visser, E. Briick, A.A. Mcnovsky, J.J.M. Franse, J. Magn. Magn. Mater 108, 63 (1992). 
${ }^{29}$ D.Bourgault, L. Porcar, C. Bruyère, P Jacquet, P. Courtois, Rev. Sci. Instr., 84, 013905 (2013).

${ }^{30}$ A. Gràcia-Condal, E. Stern-Taulats, A. Planes, E. Vives, L. Manosa, Phys. Status Solidi B 255, 1700422 (2018).

${ }^{31}$ K. Ullako, J. K. Huang, C. Kantner, R. C. O'Handley, V. V. Kokorin, Appl. Phys. Lett. 69, 1966 (1996).

${ }^{32}$ Y. Sutou, Y. Imano, N. Koeda, T. Omori, R. Kainuma, K. Ishida, K. Oikawa, Appl. Phys. Lett. 85, 4358 (2004).

${ }^{33}$ F. Gemina, Y. Sutou, R. Kainuma, K. Ishida, Metall. Mater. Trans. A 30, 2721(1999)

${ }^{34}$ L. Porcar, P. Courtois, G. Crouigneau, J. Debray, D. Bourgault, Appl. Phys. Lett. 105, 151907 (2014).

${ }^{35}$ Y. Sutou, H. Morito, S. Okamoto, O. Kitakami, K. Oikawa, A. Fujita, T. Kanomata, K. Ishida, Nature 439, 957 (2006).

${ }^{36}$ K. Koyama, H. Okada, K. Watanabe, T. Kanomata, R. Kainuma, W. Ito, K. Oikawa, K. Ishida, Appl. Phys. Lett. 89, 182510 (2006).

${ }^{37}$ S. Y. Yu, Z. H. Liu, G. D. Liu, J. L. Chen, Z. X. Cao, G. H. Wu, B. Zhang, X. X. Zhang, Appl. Phys. Lett. 89, 162503 (2006).

${ }^{38}$ L. Porcar, D. Bourgault, P. Courtois, Appl. Phys. Lett. 100, 152405 (2012).

${ }^{39}$ T. Krenke, E. Duman, M. Acet, E. F. Wassermann, X. Moya, L. Manosa, A. Planes, Nature Mater. 4, 450 (2005).

${ }^{40}$ D. Bourgault, J. Tillier, P. Courtois, D. Maillard, X. Chaud. Appl. Phys. Lett. 96, 132501 (2010).

${ }^{41}$ L. Mañosa, D. González-Alonso, A. Planes, E. Bonnot, M. Barrio, J. Tamarit, S. Aksoy, M. Acet, Nature Mater. 9, 478 (2010). 
${ }^{42}$ D. Bourgault, L. Porcar, S. Rivoirard, P. Courtois, V. Hardy, Appl. Phys. Lett.107, 092403 (2015).

${ }^{43}$ F. Guillou, P. Courtois, L. Porcar, D. Plaindoux, D. Bourgault, V. Hardy. J. Phys. D: Appl. Phys. 45, 255001 (2012).

${ }^{44}$ R. Millan-Solsona, E. Stern-Taulats, E. Vives, A. Planes, J. Sharma, A. K. Nayak, K. G. Suresh, L. Manosa, Appl. Phys. Lett. 105, 241901 (2014).

45 Z. Yang, D.Y. Cong, L. Huang, Z.H. Nie, X.M. Sun, Q.H. Zhang, Y.D. Wang, Mater. Des. 92, 932 (2016).

${ }^{46}$ Y.J. Huang, Q.D. Hu, N.M. Bruno, J. Chen, I. Karaman, J.H. Ross, J.G. Li, Scr. Mater. 105 $42(2015)$.

${ }^{47}$ B. Lu , J. Liu, Sci Rep. 18, 2084 (2017).

${ }^{48}$ V.A. Chernenko, Scripta Mater., 40, 523 (1999).

${ }^{49}$ W. Ito, Y. Imano, R. Kainuma, Y. Sutou, K. Oikawa, K. Ishida, Metall. Mater. Trans. A 38, 759 (2007).

${ }^{50}$ A. Planes, F. Perez-Reche, E. Vives, L. Manosa, Scr. Mater 50, 181 (2004).

51 W. Ito, K. Ito, R.Y. Umetsu, R. Kainuma, K. Koyama, K. Watanabe, A. Fujita, K. Oikawa, K. Ishida, T. Kanomata, Appl. Phys. Lett. 92, 021908 (2008).

${ }^{52}$ X. Xu, W. Ito, M. Tokunaga, T. Kihara, K. Oka, R.Y. Umetsu, T. Kanomata, R. Kainuma, Metals 3, 298 (2013).

${ }^{53}$ L. Porcar, P. Courtois, J. Debray, D. Bourgault, Acta Mat. 141, 83 (2017).

${ }^{54}$ S. Kustov, I. Golovin, M.L. Corro, E. Cesari, J. Appl. Phys. 107, 053525 (2010).

${ }^{55}$ H. E. Karaca, I. Karaman, B. Basaran, Y. Ren, Y. I. Chumlyakov, H. J. Maier, Adv. Funct. Mater. 19, 983 (2009).

${ }^{56}$ H. E. Karaca, I. Karaman, B. Basaran, D. C. Lagoudas, Y. Chumlyakov, H. J. Maier, Acta Mater., 55, 4253 (2007). 
${ }^{57}$ L. Manosa, A. Planes, Adv. Mater. 29, 1603607 (2017). 